\title{
A prospective randomized comparative study between trochanteric versus piriformis entry portal for intramedullary interlock nailing in the treatment of femoral shaft fracture
}

\author{
Kanta Prasad Meena*, Mahendra Kumar Yadav, Deepak Devathiya
}

Department of Orthopedics, SMS Medical College, Jaipur, Rajasthan, India

Received: 04 February 2016

Revised: 23 February 2016

Accepted: 27 February 2016

\section{*Correspondence:}

Dr. Kanta Prasad Meena,

E-mail: drkp06@gmail.com

Copyright: (C) the author(s), publisher and licensee Medip Academy. This is an open-access article distributed under the terms of the Creative Commons Attribution Non-Commercial License, which permits unrestricted non-commercial use, distribution, and reproduction in any medium, provided the original work is properly cited.

\begin{abstract}
Background: In case of close nailing for femoral shaft fractures, the nail is inserted into the medullary cavity through the proximal femur without disturbing the periosteal blood supply of at the fracture site. The piriformis fossa and greater trochanter has been commonly described as starting points for antegrade femoral nailing. The purpose of this study was to compare results of two entry ports being used for intramedullary nailing for femoral shaft fractures.

Methods: This study was conducted during a period of one year. The patients admitted with femoral diaphyseal fractures for antegrade nailing were divided in two groups alternatively for piriformis fossa entry point and greater trochanter entry point. Total number of patient in each group was $25(n=25)$. Functional outcome were analyzed at final follow up using Hari's hip score.

Results: there was no significant difference clinical and functional output in both group but intraoperative time and fluoroscopic time was significant $(\mathrm{P}<0.001)$.

Conclusions: Femoral nailing through the greater trochanter entry portal with specifically designed nails should be considered a rational alternative to femoral nailing compared to Piriformis fossa entry portal with the benefit of reduced requirement for fluoroscopy and decreased operative time in obese patients. Statistically no significant difference $(>0.005)$ in clinical and Functional outcome based on Hari's hip score.
\end{abstract}

Keywords: Fracture shaft femur, Nailing, GT entry, Piriformis entry, Harri's hip score

\section{INTRODUCTION}

Femur is the principal weight bearing bone of lower extremity and fracture of femur leads to considerable morbidity and mortality. Femoral shaft fracture results from high energy trauma which may be associated with multisystem injury and considerable soft tissue injury. Fractures of the shaft in elderly people are frequently associated with low energy trauma (e.g., falls from standing height), the main predisposing factor of which is osteoporosis
Early fixation prevents some grave complications of femoral shaft fractures like fat embolism and acute respiratory distress syndrome. It also allows for early active mobilization, which prevents hip and knee stiffness as well as quadriceps and hamstring wasting. Intramedullary nail provides predictable restoration of shaft length and alignment along with load sharing

The piriformis fossa and greater trochanter has been commonly described as starting points for antegrade femoral nailing. Because the greater trochanter is not colinear with the long axis of the femoral shaft, 
complications including various malalignment and iatrogenic fracture comminution have been demonstrated to occur when nails designed for insertion through the piriformis fossa are inserted through the greater trochanter.

Historically piriformis fossa has been commonly used as entry portal but with advent of anatomically contoured nail with a 4-degree proximal lateral bend to accommodate trochanteric entry, trochanter entry point is considered as promising alternative.

The purpose of this study was to compare results of femoral shaft fracture treatment with nailing through the greater trochanter to nailing through the PiriFormis fossa.

\section{METHODS}

The present study was conducted in S.M.S. Medical College November 2013 to march 2015 after taking clearance from the institutional ethics committee and informed consent of the subjects: The patients admitted with femoral diaphyseal fractures at OPD or emergency department of this institution were randomly selected for antegrade nailing through PF group and greater trochanter entry (GT group) approach. Total number of patient in each group was 25.

\section{Inclusion criteria}

1. Close fracture shaft of femur.

2. Type $1^{\text {st }} \&$ type $2^{\text {nd }}$ compound fracture shaft femur (gustillo-anderson).

3. Skeletally mature patient.

4. Patient giving consent for the study.

\section{Exclusion criteria}

1. Type $3^{\text {rd }}$ compound fracture shaft femur (gustilloanderson).

2. With vascular injury.

3. Pathological fractures.

4. Fractures $>3$ weeks old.

5. Medically or anaesthetically unfit patients.

6. Patient refusing consent.

\section{Implant}

All nails were cannulated, closed section, interlocking. The nails used for the GT group, was identical to those used for the PF group, with exception nail has a 4-degree proximal lateral bend to accommodate trochanteric entry. Two proximal holes for locking in head through neck, one proximal dynamic hole.

\section{Surgical technique}

The length of nail was measured from tip of greater trochanter to upper pole of patella. $2 \mathrm{~cm}$ above and below the measuring size of nail were kept during surgery. The diameter of nail to be used was measured from anteroposterior and lateral radiograph and reaming during surgery.

Supine position on fracture table, with adduction of limb, to make greater trochanter more prominent and to facilitate exposure of the proximal femur. The opposite limb was held with a knee in 90degree of flexion, hip flexed to 90 degree and abducted to 30 degree. Image intensifier unit was positioned at the unaffected site of the patient. Counter traction was provided by heavily padded perineal post.

Draping is an important part in any surgical procedure and should not be assigned to an uninitiated assistant. During draping the gloved hands should not come in contact with unprepared skin. Under all aseptic precaution, painting with betadine and draping with sterile sheets done.

For both GT entry and piriformis entry Oblique skin incision from the proximal tip of the greater trochanter and continue it proximally and posteromedially for 6-8 $\mathrm{cm}$. A longer incision may be necessary in obese patient. Superficial, deep fascia and Gluteus medius split along skin incision.

Piriformis fossa was palpated by blunt dissection. Entry point was made with curved pointed awl and medullary cavity was perforated at piriformis fossa, after confirming under image intensifier.

The Tip of greater trochanter was palpated by finger. Entry point was made with straight pointed awl and medullary cavity was perforated at tip of greater trochanter, after confirming under image intensifier.

A guide wire was passed through the proximal fragment and under $\mathrm{C}$-arm control. The fracture was reduced and guide wire was passed in to the distal fragment. If reduction was not possible by closed means then fracture site was opened through lateral incision and open reduction was done. The position was confirmed under the image intensifier in AP and lateral plane and tip of guide wire was hammered in to the subchondral bone.

After checking the fracture reduction, direct measurement of the nail was done by subtracting the exposed length of the guide wire from its overall length.

Reaming was done by manual or flexible reamer. Reaming was performed in $0.5 \mathrm{~mm}$ increments up to $1 \mathrm{~mm}$ diameter larger than the chosen nail to make nail passage easier. After reaming exchange tube passed over guide wire $\mathrm{n}$ ball tip guide wire changed by pointed guide wire.

The position of the guide wire was then checked both in $\mathrm{AP}$ and lateral views with image intensifier and the guide wire was removed. A rotational alignment was checked clinically, intra-operatively. 
The chosen nail was then mounted on the jig and the nail was introduced over the guide wire and inserted using a hammer. The position of the nail was then checked both in AP and lateral views with image intensifier and the guide wire was removed. A rotational alignment was checked clinically, intra-operatively.

Proximal locking in both was done with the help of proximal jig. A drill sleeve was then passed into the guide sleeve and The cortex was drilled using a $4 \mathrm{~mm}$ drill bit and a drill hole was made through both the cortices, the length of the screw needed was determined using a depth gauge and the $4.5 \mathrm{~mm}$ proper size screw was inserted through the guide sleeve. The second screw was placed in the similar manner. If there was fracture neck of femur of intertrochenter fracture proximal locking in head through neck was done by oblique holes in proximal part of greater trochanter entry portal nail.

After removal of proximal jig limb abducted for distal locking.
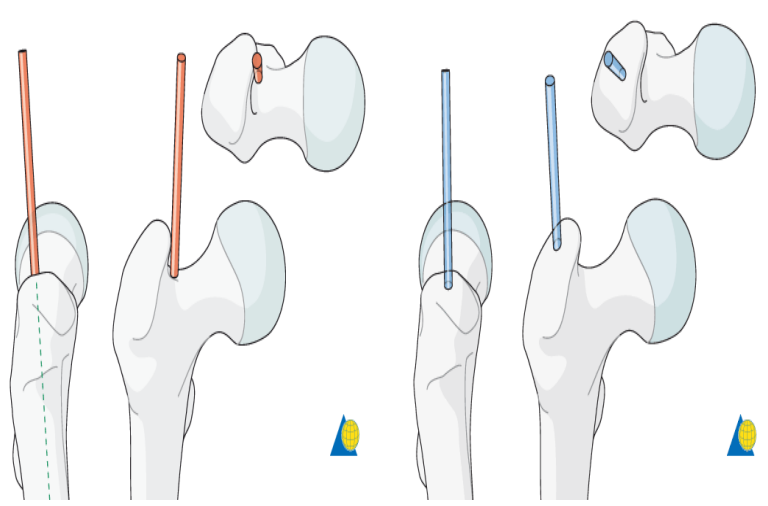

Figure 1: Entry points for interlocking nail in femur.

In both entry portal nails distal locking was done with a free hand technique and using C-arm. A K-wire was used to make a track in the center of the screw hole under $\mathrm{C}$ arm; the screw hole was drilled through the same track.
The screw length was measured and the screw was inserted.

Finally the whole length of the nail, reduction, proximal, and distal locking screws were checked under image intensifier.

The incised wounds were washed with betadine and normal saline and were sutured in layer. Sterile pads were put and compression bandage was applied.

\section{Rehabilitation}

Emphasis was placed postoperatively on muscle strengthening of the thigh as well as on the range of motion (ROM) of the knee. Active hip and knee ROM exercises were started as soon as pain subsided, usually 24-48 h after operation. Patients were ambulated within 24-48 h after surgery using toe-touching bilateral axillary crutches in cases of stable fracture and satisfactory stable fixation. Suture removal was done after 2 weeks of surgery, on the first postoperative visit. Guarded weight bearing was allowed as soon as bridging callus was seen in X-ray, usually after 4-6 weeks. Full weight bearing was started when the fracture site was completely bridged by callus and fracture site clinically became nontender. Patients were then examined at 6 weekly intervals until absolute fracture union was obtained clinicoradiographically. Patients were followed up at 6 months and 1-year. Patients who did not show normal periosteal bridging callus at end of 3 months after injury were followed up seen at 4-6 week intervals. If delayed or absent healing were noted at 4-5 months after injury, consideration was given to convert a statically locked nail to a dynamic mode by removing dynamic bolt or both the bolts.

Patients were evaluated both clinically and radiologically using criteria by Harris Hip scoring system at 12 month postoperatively.

\section{RESULTS}

Table 1: Distribution according to age \& sex of group-A \& group-B subjects.

\begin{tabular}{|c|c|c|c|c|c|c|}
\hline \multirow{2}{*}{$\begin{array}{l}\text { Age } \\
\text { group (In } \\
\text { years) }\end{array}$} & \multicolumn{3}{|l|}{ Group-A } & \multicolumn{3}{|l|}{ Group-B } \\
\hline & $\mathrm{M}$ & $\mathrm{F}$ & Total & M & $\mathrm{F}$ & Total \\
\hline$<40$ & $19(76.00)$ & $1(4.00)$ & $20(80.00)$ & $16(64.00)$ & $3(12.00)$ & $19(76.00)$ \\
\hline$\geq 40$ & $5(20.00)$ & $0(0.00)$ & $5(20.00)$ & $5(20.00)$ & $1(4.00)$ & $6(24.00)$ \\
\hline Total & $24(96.00)$ & $1(4.00)$ & $25(100.00)$ & $21(84.00)$ & $4(16.00)$ & $25(100.00)$ \\
\hline
\end{tabular}




\section{Mode of injury}

Table 2: Distribution according to mode of injury of group-A \& group-B subjects.

\begin{tabular}{|lll|l|}
\hline $\begin{array}{l}\text { Mode of } \\
\text { injury }\end{array}$ & \multicolumn{2}{c|}{ Group } & Total \\
\hline RTA & $24(96.00)$ & $23(92.00)$ & $47(94.00)$ \\
\hline FFH & $0(0.00)$ & $2(8.00)$ & $2(4.00)$ \\
\hline Slip \& Fall & $1(4.00)$ & $0(0.00)$ & $1(2.00)$ \\
\hline Total & $25(100.00)$ & $25(100.00)$ & $50(100.00)$ \\
\hline
\end{tabular}

\section{Fracture characteristics}

Table 3: Distribution according to fracture closed or open.

\begin{tabular}{|llll|}
$\begin{array}{l}\text { Type of } \\
\text { Fracture }\end{array}$ & \multicolumn{2}{c}{ Group } & Total \\
\hline Close & $23(92.00)$ & $22(88.00)$ & $45(90.00)$ \\
\hline Open & $2(8.00)$ & $3(12.00)$ & $5(10.00)$ \\
\hline Total & $25(100.00)$ & $25(100.00)$ & $50(100.00)$ \\
\hline
\end{tabular}

Table 4: Distribution according to winquist classification.

\begin{tabular}{|llll|}
\hline $\begin{array}{l}\text { Fracture } \\
\text { grade }\end{array}$ & Group & & Total \\
\hline Winquist-1 & $16(64.00)$ & $16(64.00)$ & $32(64.00)$ \\
\hline Winquist-2 & $5(20.00)$ & $6(24.00)$ & $11(22.00)$ \\
\hline Winquist-3 & $3(12.00)$ & $2(8.00)$ & $5(10.00)$ \\
\hline Winquist-4 & $1(4.00)$ & $1(4.00)$ & $2(4.00)$ \\
\hline Total & $25(100.00)$ & $25(100.00)$ & $50(100.00)$ \\
\hline
\end{tabular}

\section{Operative and fluoroscopy times}

Table 5: Mean \pm SD of operation time and fluoroscopy time for entry (shots) of group-A \& group-B subjects.

\begin{tabular}{|c|c|c|c|c|}
\hline & \multicolumn{2}{|c|}{ Mean \pm SD } & \multirow{2}{*}{$\begin{array}{l}\text { P- } \\
\text { value }\end{array}$} & \multirow[b]{2}{*}{ Significance } \\
\hline & $\begin{array}{l}\text { Group- } \\
\text { A }\end{array}$ & $\begin{array}{l}\text { Group- } \\
\text { B }\end{array}$ & & \\
\hline $\begin{array}{l}\text { Operation } \\
\text { time (In min) }\end{array}$ & $\begin{array}{l}64.20 \\
\pm 4.25\end{array}$ & $\begin{array}{l}76.44 \\
\pm 4.44\end{array}$ & $<0.001$ & HS \\
\hline $\begin{array}{l}\text { fluoroscopy } \\
\text { time for } \\
\text { entry(Shots) }\end{array}$ & $\begin{array}{l}5.88 \pm \\
1.39\end{array}$ & $\begin{array}{l}10.08 \\
+3.13\end{array}$ & $<0.001$ & HS \\
\hline
\end{tabular}

Table 6: Distribution according to body mass index.

\begin{tabular}{|lll|}
\hline \multirow{2}{*}{ Body mass index } & \multicolumn{2}{c|}{ Group } \\
\hline$\leq 30$ & Pf group & Gt group \\
\hline$\geq 30$ & 20 & 19 \\
\hline
\end{tabular}

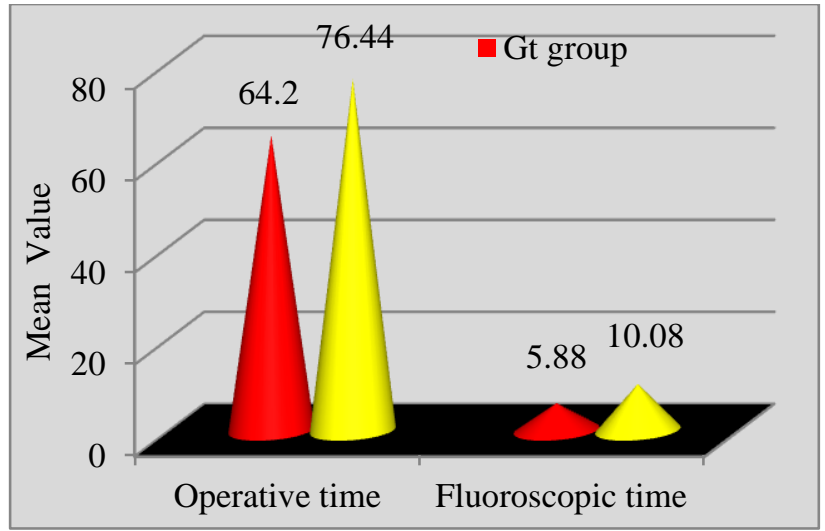

Figure 2: Mean \pm SD of operation time and fluoroscopy time for entry (shots) of group-A \& group-B subjects.

Table 7: Operative and fluoroscopy times in obese patients.

\begin{tabular}{|c|c|c|c|c|}
\hline & $\begin{array}{l}\text { Gt } \\
\text { group }\end{array}$ & $\begin{array}{l}\text { Pf } \\
\text { group }\end{array}$ & $\begin{array}{l}\text { p- } \\
\text { value }\end{array}$ & Significance \\
\hline $\begin{array}{l}\text { Operative } \\
\text { time }\end{array}$ & $\begin{array}{l}69.50 \\
\pm \\
2.26\end{array}$ & $\begin{array}{l}82.40 \\
\pm 8.17\end{array}$ & $\begin{array}{l}< \\
.001\end{array}$ & HS \\
\hline $\begin{array}{l}\text { Fluoroscopic } \\
\text { time }\end{array}$ & $\begin{array}{l}7.33 \\
\pm \\
1.21\end{array}$ & $\begin{array}{l}14.00 \\
\pm 4.18\end{array}$ & $\begin{array}{l}< \\
0.01\end{array}$ & Sig \\
\hline
\end{tabular}

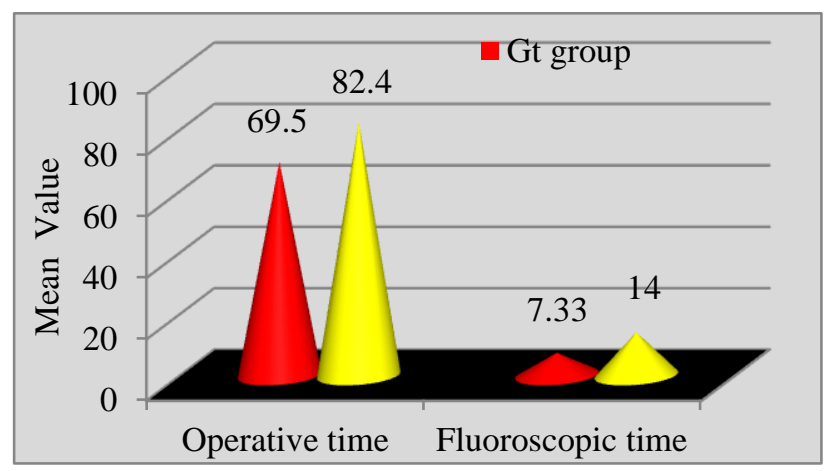

Figure 3: Operative and fluoroscopy times in obese patients.

The mean operative time for the PF group was 76.44 minutes (range 50-108minutes); for the GT group it was 64.20 minutes (range 40-102). The mean fluoroscopy time for entry portal in the PF group was 10.08 (range 218 ); for the GT group it was 5.88 seconds (range 2-15). This increase in fluoroscopy and operating time for the $\mathrm{PF}$ group was significant.

These differences were magnified in patients who were obese (body mass index $>30$ ) where the operative time $(\mathrm{pf}=82.40, \mathrm{gt}=69.50)$ and the fluoroscopy time was higher ( $\mathrm{pf}=14, \mathrm{gt}=7.33)$ in the PF group. 
Table 8: Distribution according to type of post-OP complications of group-A \& group-B subjects.

\begin{tabular}{|lll|l|}
\hline $\begin{array}{l}\text { Type of } \\
\text { complication }\end{array}$ & $\begin{array}{l}\text { Group } \\
(\mathrm{n}=25)\end{array}$ & $\begin{array}{l}\text { B } \\
(\mathrm{n}=25)\end{array}$ & Total \\
\hline Delayed union & $3(12.00)$ & $1(4.00)$ & $4(8.00)$ \\
\hline Non union & $0(0.00)$ & $2(8.00)$ & $2(4.00)$ \\
\hline Infection & $0(0.00)$ & $1(4.00)$ & $1(2.00)$ \\
\hline Broken nail & $1(4.00)$ & $0(0.00)$ & $1(2.00)$ \\
\hline Total & $4(16.00)$ & $4(16.00)$ & $8(16.00)$ \\
\hline
\end{tabular}

22 of the 25 fractures from the GT group (88\%) and 21 of the 25 fractures from the PF group (84\%) healed after the index procedure.

3 patients in the GT group had delayed union in which 2 patients fracture unite after dynamisation and one patient had non-union with broken nai which is healed after exchange nail with bone graft.

In the PF group 4 patients had delayed unions. In which one patient from the pf group unite after dynamisation and one had infection which was united after debridement and antibiotic cement beads. Two patients from the PF group had non-union and healed after exchange nailing.

Table 9: Distribution according to outcome of groupA \& group-B subjects at 12 month.

\begin{tabular}{|llll|}
\hline \multirow{2}{*}{ Outcome } & Group & & Total \\
\cline { 2 - 3 } & A & B & \\
\hline Excellent & $23(92.00)$ & $21(84.00)$ & $44(88.00)$ \\
\hline Good & $1(4.00)$ & $4(16.00)$ & $5(10.00)$ \\
\hline Total & $1(4.00)$ & $0(00)$ & $1(2.00)$ \\
\hline
\end{tabular}

$\mathrm{X} 2=0.803 ;$ d.f $=1 ; \mathrm{P}>0.05 ; \mathrm{NS}$

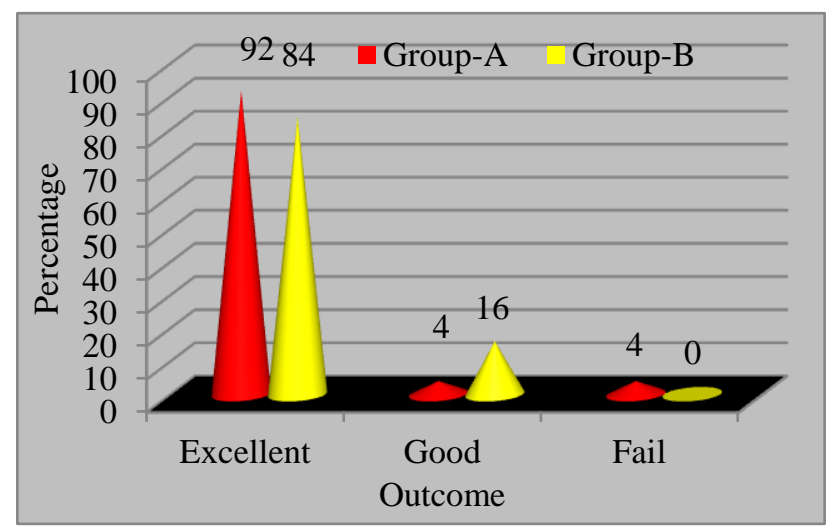

Figure 4: Distribution according to outcome of groupA \& group-B subjects at 12 month.

\section{DISCUSSION}

Kuntscher originally popularized the technique of closed antegrade intramedullary nailing using an open section, straight, cloverleaf nail for fractures of the femoral shaft. ${ }^{1}$
He suggested the lateral decubitus position and the use of the tip of the greater trochanter as the preferred entry portal to minimize risks such as intracapsular infection, avascular necrosis of femoral head, and iatrogenic femoral neck fracture.

The entry portal was further refined by Bohler stated: "the awl is placed on the greater trochanter at the junction of the middle and posterior third. ${ }^{2}$

The AO study group noted that "the nail should not be introduced through the top of the greater trochanter, but somewhat more laterally, so that neither the retinacular vessels nor the hip joint are damaged. The major problems associated with placing a straight nail (i.e., without a trochanteric bend) through these starting points was comminution of the medial femoral cortex of the proximal fragment and various fracture malalignment, especially for proximal fractures.

The piriformis fossa starting point became the standard for antegrade nailing since Winquis et al indicated they "strongly preferred" this starting point with the patient in the lateral decubitus position. ${ }^{3}$ Although no specific data were presented, they described eccentric reaming of the medial cortex of the proximal fragment and comminution of the fracture site, especially in the more proximal fractures or various malalignment when the lateral starting point that Kuntscher had advised was used. However, the piriformis fossa entry point continues to be used. The main advantage of a PF starting point is its collinear alignment with the long axis of the femoral shaft. This reduces the risk of iatrogenic fracture comminution and various malalignment compared to offaxis entry points such as trochanteric entry points. Disadvantages of this entry point include relative technical difficulty obtaining the proper entry site, especially in obese patients. This difficulty also reflected in comparatively higher operative time and fluoroscopy shots required in this entry portal. This entry point is also very sensitive to anterior-posterior translation, with anterior positioning being associated with extreme hoop stresses increased risk of iatrogenic bursting of the proximal segment, with medial positioning being associated with increased risk of iatrogenic fracture of neck of femur.

This result corroborates with study of Ricci et al One hundred and eight patients were treated with either nailing through a greater trochanter starting point with the trigen TAN nail (GT group) $(\mathrm{n}=38)$ or through a $\mathrm{PF}$ starting point with the trigen FAN nail (PF group) ( $\mathrm{n}=$ 53). ${ }^{10,11}$ Thirty seven of the 38 fractures from the GT group and 52 of the 53 fractures from the PF group healed after the index procedure. One patient from the GT group had external rotation malalignment of $12^{\circ}$. There were no other malalignment or iatrogenic fracture comminution. 
There were 2 infectious complications, 1 from each group. The average operative time was $75 \mathrm{~min}$ for piriformis insertion using the FAN nail and 62 min for trochanteric insertion using the TAN nail $(\mathrm{P}=0.08)$.

The average fluoroscopy time was $61 \%$ greater for the PF group (153 s) than for the GT group (95 s) (P: 0.05). These differences were magnified in patients who were obese (body mass index. 30) where the operative time was $30 \%$ greater $(\mathrm{P}, 0.05)$ and the fluoroscopy time was $73 \%$ higher in the PF group (P, 0.02). Patients from both groups had a similar initial decline and subsequent improvement in function overtime $(\mathrm{P}<0.05)$.

A retrospective clinical and radiographic review by Keeler et al of 78 children and adolescents with 80 femoral shaft fractures who underwent IM nail fixation through the lateral aspect of the greater trochanter, with a mean follow-up of 99 weeks, was performed. ${ }^{13}$ All patients went on to union in good clinical alignment without loss of reduction. No nonunions, delayed unions or malunions were observed. Two patients developed infections postoperatively $(2.5 \%)$.

Gosh et al the mean operative time of piriformis entry nailing and trochanteric entry nailing was $112.7 \mathrm{~min}$. and 90.7 min. respectively. ${ }^{15}$ This difference in operative time was statistically significant $(\mathrm{P}=0.005)$. The average number of $\mathrm{C}$-arm shots to perform the entry point in piriform fossa is significantly higher as compared to trochanter (mean is 10 and 8 respectively; $\mathrm{P}=0.048$ ). One patient in either group develops superficial wound infection, which was successfully treated by repeated dressing and oral antibiotics according to culture sensitivity report. One patient in piriformis entry group developed deep infection at proximal locking bolt site which was managed by bolt removal, sinus tract excision and parenteral antibiotic injections according to culture sensitivity report.

About $93.3 \%$ patients of piriformis entry group and $100 \%$ patients of trochanteric entry showed union after index procedure. There was no statistically significant difference in union rates between two study groups. Majority of piriform entry $(85.7 \%)$ and trochanter entry $(80 \%)$ patients showed radiological union before 20 weeks $(\mathrm{P}=0.92)$.

In this study majority of cases of PE group and GTE group could be allowed for full weight bearing between 16-19 weeks (42.8\%) and20-23 weeks (40\%) respectively $(\mathrm{P}=0.803)$. $\mathrm{ROM}$ of hip and knee joint in the study subjects were almost within normal limits. However, abduction loss within $10^{\circ}-20^{\circ}$ range is slightly higher among the GTE group (13.3\%) than the PE group but it was statistically insignificant $(P=0.47)$. Two patient in the PE group and three patients in GTE group had limb length discrepancies (0.69) but all limb shortenings were within an acceptable range $(\leq 2 \mathrm{~cm})$. Two patients in PE group and three patients in GTE group had hardware prominences. Among them, one patient of either group had prominence at distal locking site; one case in PE group and three cases in GTE group had nail prominence at entry sites but this difference had no statistical significance $(\mathrm{P}=41)$.

Functional status assessment was done using Thoresen's Scoring System. Excellent functional status was seen more in the PE group (85.7\%) than the GTE group (80\%) but this had no statistical significance $(P=68)$.

In our study, the mean operative time of piriformis entry nailing and trochanteric entry nailing was $76.44 \mathrm{~min}$. and $64.20 \mathrm{~min}$. respectively which is statistically highly significant $(\mathrm{P}<0.001)$. The average number of $\mathrm{C}$-arm shots to perform the entry point in piriform fossa is significantly higher as compared to trochanter (mean is 10.08 and 5.88 respectively) $(\mathrm{P}<0.001)$.in obese patient The mean operative time(69.50 and 82.40) and The average number of C-arm shots(7.33 and 14) less in Gt group then $\mathrm{PF}$ group.

Twenty two of the 25 fractures from the GT group (88\%) and 21 of the 25 fractures from the PF group (84\%) healed after the index procedure. majority of cases of PF group and GT group could be allowed for full weight bearing between 19-21 weeks. ROM of hip and knee joint in the study subjects were almost within normal limits.

Three patients in the GT group had delayed union in which 2 patients fracture unite after dynamisation and one patient had non-union with broken nail which is healed after exchange nail with bone graft.

In the PF group 4 patients had delayed unions. In which one patient from the PF group unite after dynamisation and one had infection which was united after debridement and antibiotic cement beads. Two patients from the PF group had non-union and healed after exchange nailing.

Functional status assessment was done using HARRIS HIP Scoring System. Excellent functional status (92\% and $84 \%$ ) and good functional status (4\% and 16\%) was seen in the gt group and the pf group.

\section{CONCLUSION}

In conclusion, the use of a femoral nail specifically designed for trochanteric insertion eliminated complications previously seen when this starting point was used with nails straight in the coronal plane. Our results indicate an excellent rate of union, no iatrogenic fracture comminution.

Healing rates, complication rates, and functional results were similar to those found with antegrade nailing through the piriformis fossa.

Based on these results, femoral nailing through the greater trochanter with specifically designed nails and 
with attention to specific techniques for such insertion should be considered a rational alternative to femoral nailing through the piriformis fossa with the benefit of reduced requirement for fluoroscopy and decreased operative time in patients who are obese.

Trochentric entry nail can also be used in case of femur shaft fracture associated with ipsilateral intertrochenter fracture or fracture neck of femur.

Funding: No funding sources Conflict of interest: None declared

Ethical approval: The study was approved by the Institutional Ethics Committee

\section{REFERENCES}

1. Küntscher G. Die makknaelunguon knochen. Langenbecks Archive Klin Chir. 1940;200:443-55.

2. Bohler L, Bohler J: Kütscher's medullary nailing. J Bone Joint Surg Am. 1949;31:295-305.

3. Winquist RA, Hansen ST Jr, Clawson DK: Closed intramedullary nailing of femoral fractures. A report of five hundred and twenty cases. J Bone Joint Surg Am. 1984;66:529-39.

4. Harper MC, Carson WL: Curvature of the femur and the proximal entry point for an intramedullary rod. Clin Orthop Relat Res. 1987;220:155-61.

5. McKee MD, Waddell JP: Intramedullary nailing of femoral fractures in morbidly obese patients. J Trauma. 1994;36:208-10.

6. Ostrum RF: A greater trochanteric insertion site for femoral intramedullary nailing in lipomatous patients. Orthopedics. 1996;19:337-40.

7. Gausepohl T, Pennig D, Koebke J, Harnoss S. Antegrade femoral nailing: an anatomical determination of the correct entry point. Injury. 2002;33:701-5.

8. Ansari Moein CM, Verhofstad MH, Bleys RL, van der Werken C: Soft tissue injury related to choice of entry point in antegrade femoral nailing: piriform fossa or greater trochanter tip. Injury. 2005;36:133742.

9. Ostrum RF, Marcantonio A, Marburger R: A critical analysis of the eccentric starting point for trochanteric intramedullary femoral nailing. J Orthop Trauma, 19: 681-686, 2005.

10. Ricci WM, Devinney S, Haidukewych G, Herscovici D,Sanders R: Trochanteric nail insertion for the treatment of femoral shaft fractures. J Orthop Trauma. 2005;19:511-7.

11. Ricci WM, Schwappach J, Tucker M. Trochanter versus piriformis entry portal for the treatment of femoral shaft fractures. J Orthop Trauma. 2006;20:663-7.

12. Starr AJ, Hay MT, Reinert CM, Borer DS, Christensen KC. Cephalomedullary nails in the treatment of high-energy proximal femur fractures in young patients: a prospective, randomized comparison of trochanteric versus piriformis fossa entry portal. J Orthop Trauma. 2006;20:240-6.

13. Keeler KA, Dart B, Luhmann SJ, Schoenecker PL, Ortman MR,Dobbs MB, et al. Antegrade intramedullary nailing of pediatric femoral fractures using an interlocking pediatric femoral nail and a lateral trochanteric entry point. J Pediatr Orthop. 2009;29:345-51.

14. Stannard JP, Bankston L, Futch LA, McGwin G,Volgas DA: Functional outcome following intramedullary nailing of the femur: a prospective randomized comparison of piriformis fossa and greater trochanteric entry portals. J Bone Joint Surg Am. 2011;93:1385-91.

15. Ghosh S, Das J, Chaudhuri A, Kumar A, Datta S, De C. Comparative study of treatment of fracture shaft femur by intramedullary interlocking nails through piriform fossa entry and tip of the greater trochanter entry approach. Saudi J Sports Med. 2015;15:148-52.

Cite this article as: Meena KP, Yadav MK, Deepak. A prospective randomized comparative study between trochanteric versus piriformis entry portal for intramedullary interlock nailing in the treatment of femoral shaft fracture. Int J Res Orthop 2016;2:18-24. 